\title{
Democratização do ensino e o fracasso escolar
}

Democratization of teaching and school failure

Democratización de la enseñanza y fracaso escolar

Karina Barreto Silva - Centro Universitário Una | Mestranda no Programa de Pós-Graduação em Gestão Social, Educação e Desenvolvimento Local | Belo Horizonte | MG | Brasil. E-mail: kkpedagoga@ yahoo.com.br

Maria Lúcia Miranda Afonso - Centro Universitário Una | Programa de Pós-Graduação em Gestão Social, Educação e Desenvolvimento Local | Belo Horizonte | MG | Brasil. E-mail: luafonso@yahoo.com (1) orciD

Resumo: O presente artigo tem como objetivo realizar uma reflexão sobre o fracasso escolar, abordando o papel do professor e da escola no processo de ensino-aprendizagem, bem como relacionar a democratização e a qualidade do ensino a partir da inserção de segmentos populares na escola, em um modelo educacional que tradicionalmente prioriza as elites políticas e econômicas. Para isto, discute conceitos como inovação, desenvolvimento local na educação e adequação do currículo sob uma perspectiva democrática. Como metodologia, recorreu-se aos estudos de diferentes autores, localizados em sítios de busca cientifica, a partir das expressões "fracasso escolar", "inovação educacional" e "desenvolvimento local". Sob a análise dessas investigações, chegou-se a algumas constatações: a insuficiência de estudos sobre o fracasso escolar ; a necessidade de investimento por parte do professor em ações que mobilizem os alunos para o aprendizado; a importância da reflexão sobre o conceito de inovação no âmbito educacional; e os impactos do desenvolvimento local na educação.

Palavras-chave: Fracasso escolar. Inovação educacional. Desenvolvimento local.

Abstract The present article aims to reflect on school failure addressing the role of the teacher and the school in the teachinglearning process, as well as to relate the democratization and quality of teaching through the insertion of popular segments in school, whithin an educational model that traditionally prioritizes political and economic elites. It discusses concepts such as innovation, local development in education and curriculum adequacy from a democratic perspective. As methodology, we resorted to the studies of different authors, looking at scientific sites for the expressions "school failure", "educational innovation" and "local development". Under the analysis of these investigations, we found the following results: the insufficiency of Brazilian studies about school failure; the need for investment by the teacher in actions that mobilize students for learning; the importance of reflection on the concept of innovation in education; and the impacts of local development on education.

Keywords: School failure. Educational innovation. Local development.

Resumen: El presente artículo tiene como objetivo realizar una reflexión sobre el fracaso escolar, abordando el papel del profesor y de la escuela en el proceso de enseñanza-aprendizaje, así como relacionar la democratización y la calidad de la enseñanza a partir de la inserción de segmentos populares en la escuela, en un modelo educativo que tradicionalmente prioriza las elites políticas y económicas. Para ello, discute conceptos como innovación, desarrollo local en la educación y adecuación del currículo desde una perspectiva democrática. Como metodología, se recurrió a los estudios de diferentes autores, localizados en sitios de búsqueda científica, a partir de las expresiones "fracaso escolar", "innovación educativa" y "desarrollo local". Bajo el análisis de estas investigaciones, se llegó a algunas constataciones: la insuficiencia de estudios sobre el fracaso escolar; la necesidad de inversión por parte del profesor en acciones que movilicen a los alumnos para el aprendizaje; la importancia de la reflexión sobre el concepto de innovación en el ámbito educativo; y los impactos del desarrollo local en la educación.Palabras clave:

Palabras clave: Fracaso escolar. Innovación educativa. Desarrollo local.

- Recebido em 30 de abril de 2018 • Aprovado em 15 de maio de $2019 \cdot$ e-ISSN: 2177-5796

DOI: http://dx.doi.org/10.22483/2177-5796.2019v21n2p649-669

Copyright @ 2019. Conteúdo de acesso aberto, distribuído sob os termos da Licença Internaonal da CreativeCommons - CC BY-NC-SA Atribuição Não Comercial (https://br.creativecommons.org/licencas/) - Permite distribuição e reprodução, desde que atribuam os devido créditos à publicação, ao autor(es) e que licenciem as novas criações sob termos idênticos. 


\section{Introdução}

O processo de democratização do ensino contribuiu para a inserção das camadas populares nas instituições educacionais, e trouxe grandes avanços e desafios para a educação pública brasileira. Entre os desafios a serem enfrentados, podemos elencar a adequação do currículo, a discussão sobre a qualidade do ensino ofertado e o enfrentamento do fracasso escolar. Este artigo tem como objetivo realizar uma reflexão sobre o fracasso escolar, abordando o papel do professor e da escola no processo de ensino-aprendizagem, e discutindo conceitos como inovação e desenvolvimento local na educação. Para isto, recorreu-se aos estudos de diferentes autores - Vítor Henrique Paro (2000, 2007, 2012), Miguel Arroyo (1999, 2000), Bernard Charlot (1996, 2000, 2005), José Carlos Libâneo (2002, 2005, 2011, 2013), Jaume Carbonell (2002) e António Fragoso (2005), localizados em sítios de busca, a partir das expressões "fracasso escolar", "inovação educacional” e "desenvolvimento local".

O presente artigo foi construído a partir do desenvolvimento do trabalho de pesquisa realizado durante o curso de Mestrado Profissional do Programa de Pós-Graduação em Gestão Social, Educação e Desenvolvimento Local, do Centro Universitário Una. Para subsidiar a discussão, o texto foi organizado em três partes, além das considerações finais.

Na primeira parte, foi feita uma discussão sobre a democratização da escola, e sobre a necessidade de se refletir criticamente a respeito dos objetivos do ensino e sua relação com as necessidades dos alunos, problematizando a questão do fracasso escolar.

$\mathrm{Na}$ segunda parte do artigo foi abordada a importância da ação do professor como mediador no processo de ensino e aprendizagem, a relação que o aluno constrói com o saber, o conceito de desenvolvimento local e sua articulação com uma educação voltada para a formação cidadã.

Na terceira parte, apresenta-se o conceito de inovação, problematizando, à luz da prática profissional da pesquisadora, as questões que se confundem com o conceito de inovação.

Nas considerações finais, buscou-se desenvolver uma articulação entre os diferentes pontos de vista analisados, representados pelos autores já, mencionados nesta introdução, na tentativa de contribuir para um debate sobre as práticas desenvolvidas nas escolas à luz das contribuições teóricas sobre a democratização do ensino e qualidade da educação pública. 


\section{Relações fracasso escolar, democratização e qualidade do ensino}

Nos últimos anos, observam-se vários avanços voltados para a área da educação no Brasil, principalmente com relação à democratização do ensino, garantida pela Lei de Diretrizes e Bases da Educação Nacional (LDB) - Lei 9.394 (BRASIL, 1996). Essa lei prevê a gratuidade do ensino público, a igualdade de condições para o ingresso e a permanência na escola e trouxe avanços significativos de acesso à educação para classes discriminadas e vulneráveis. Houve a ampliação da oferta do ensino, aumentou-se o número de escolas e todas as crianças e adolescentes passaram a ter assegurado por legislação o direito à Educação Básica.

O processo de democratização do ensino no Brasil trouxe grandes avanços do ponto de vista social, mas também grandes desafios a serem enfrentados, devido à complexidade dos problemas que se apresentam no âmbito escolar. A escola tradicional é extremamente conservadora e seletiva, e até então não se deparava com os problemas que hoje são evidenciados no sistema educacional brasileiro, com o atendimento a alunos vindos de classes sociais até então suprimidas da escola. Como observa Libâneo (2002), é importante fazer com que a conquista da escolarização por crianças de classes populares represente não só o acesso, mas sua permanência bem sucedida na escola. Em meio às discussões sobre democratização do ensino, um aspecto que se configura como "um pesadelo que cerca as escolas", utilizando uma expressão de Miguel González Arroyo (2000) é o fracasso escolar. Arroyo observa que não é possível desconsiderar este aspecto, que está

[...] quantificado nas taxas de reprovação e defasagem dos alunos, e que em cada momento social adquire novo sentido. Assim, a temática do fracasso escolar surge como demanda importante nas discussões fomentadas pelos educadores que almejam associar a democratização do ensino com uma educação de qualidade (ARROYO, 2000, p.36)

Segundo Libâneo (2011), devem ser considerados os progressos sociais que a escola brasileira vem apresentando nas últimas décadas, principalmente quanto à universalização e atendimento das crianças em idade escolar, porém é preciso assegurar a permanência do aluno e a qualidade do ensino na escola. Este autor enfatiza que dados estatísticos demonstram que as crianças e os jovens, mesmo quando encerram o seu processo de escolarização, não apresentam mudanças perceptíveis na sua formação geral ou na qualidade de suas aprendizagens escolares.

No bojo desta discussão sobre a qualidade das aprendizagens, Paro (2007) observa que o descontentamento generalizado com a qualidade do ensino público tem a ver com a dissociação 
SILVA, Karina Barreto; AFONSO, Maria Lúcia Miranda. Democratização do ensino e o fracasso escolar.

entre a teoria e a prática, entre o que se espera alcançar com o ensino e o que efetivamente é alcançado. Segundo o autor, o conceito de qualidade no ensino não é consensual e pode adquirir diferentes nuances, de acordo com os objetivos que o ensino pretende alcançar. Isto explicaria o que é entendido como má qualidade:

Visto que esta depende dos objetivos que se pretende buscar com a educação, quando estes não estão suficientemente explicitados e justificados pode acontecer de, em acréscimo à não correspondência entre medidas proclamadas e resultados obtidos, estarse empenhando na realização dos fins errados ou não inteiramente de acordo com o que se pretende (PARO, 2007, p. 15).

A importância desta discussão está em se identificar quais são os objetivos a que o ensino público tem se dedicado a alcançar. Ao analisar a forma como historicamente o processo de escolarização ocorreu no Brasil, percebe-se que os contingentes que não foram inseridos ao longo dos anos, ou que foram incluídos sob a perspectiva de uma preparação mínima para o mercado de trabalho, não participaram da construção dos objetivos da educação pública. Estes objetivos foram estabelecidos a partir de necessidades específicas, que ainda hoje determinam as funções da escola. Paro (2007) defende a necessidade de se fazer uma análise crítica das concepções que povoam as proposições de objetivos e currículos escolares:

Os múltiplos pontos de vista, nem sempre explícitos, e a imprecisão e mesmo superficialidade de diversas produções sobre o tema têm concorrido para a falta de rigor nos discursos e nos propósitos sobre o real papel da escola - que em nada contribui para uma visão realista do que se pretende e se deve defender como um a educação de acordo com os interesses do cidadão e da sociedade, servindo apenas àqueles interessados em protelar soluções ou em impor o ponto de vista dos donos do poder político e econômico. Nesse particular, é preciso não apenas fazer a revisão crítica das concepções existentes, em especial o paradigma neoliberal que associa o papel da escola ao atendimento das leis de mercado, mas principalmente contribuir para a elaboração de um conceito de qualidade que valha a pena ser posto como horizonte e que sirva de parâmetro para a proposição de políticas públicas consistentes e realistas para o ensino fundamental (PARO, 2007, p. 20).

Sendo assim, o papel da educação pública e a qualidade do ensino são temas que se relacionam com os objetivos de ensino estabelecidos e as concepções de sociedade que são desenhadas na definição dos currículos e das metodologias. Daí, a aparente dissonância entre os objetivos pretendidos para o ensino público e os resultados obtidos sugere que o conhecimento que se pretende construir deve se articular com as necessidades e interesses dos cidadãos que são parte essencial do processo. 
Ao estabelecer objetivos de ensino que não se articulam com as necessidades dos alunos, o sistema educacional faz com que o aluno estabeleça um tipo de relação com o conhecimento que pode não dialogar com o que os sujeitos de fato precisam aprender. E, neste sentido, o conceito de qualidade passa a considerar não as necessidades dos alunos, mas, como analisa Paro (2007), as necessidades dos donos do poder político e econômico. Isto leva a um processo de culpabilização infrutífero, que responsabiliza as famílias, o meio social e cultural do aluno ou a má qualidade de formação dos professores, mas que não aprofunda na discussão crítica sobre o conceito de qualidade e sobre as demandas que a sociedade apresenta.

Preocupado em responder o que significa o fracasso escolar nos meios populares, o filósofo, pesquisador e escritor do sistema escolar francês, Bernard Charlot, debruçou-se sobre questões inquietantes sobre o fracasso escolar:

Por que será que certos alunos fracassam na escola? Por que será que esse fracasso é mais frequente entre as famílias de categorias sociais populares do que em outras famílias? Mais ainda: por que será que certas crianças dos meios populares alcançam, apesar de tudo, sucesso em seus estudos, como se elas conseguissem esguiar-se pelos interstícios estatísticos? (CHARLOT, 2000, p. 9).

As questões que serviram de motivação para as investigações desenvolvidas por esse autor no meio educacional permanecem, intrigam e parecem, todavia, não ter respostas dentro das instituições escolares, principalmente naquelas que se encontram em áreas de periferia urbana e nas quais a maior parte dos alunos tende a não conseguir alcançar êxito em sua trajetória escolar. Sobre o fracasso escolar, Charlot ressalta que:

A questão do fracasso escolar remete para muitos debates: sobre o aprendizado, obviamente, mas também sobre a eficácia dos docentes, sobre o serviço público, sobre a igualdade das "chances", sobre os recursos que o país deve investir em seu sistema educativo, sobre a "crise", sobre os modos de vida e o trabalho na sociedade de amanhã, sobre as formas de cidadania, etc. (CHARLOT, 2000, p. 14).

De acordo com Charlot, “o 'fracasso escolar' não existe; o que existe são alunos fracassados, situações de fracasso, histórias escolares que terminam mal” (2000, p. 16). O fracasso escolar, segundo o autor, não pode, portanto, ser tomado como objeto de pesquisa. Devese, por conseguinte, analisar os alunos, o conjunto de fenômenos observados e as condições que compõem o quadro de insucesso dos processos de ensino aprendizagem. Esses são fatores que merecem atenção e devem ser investigados. Ainda de acordo com esse pesquisador: 
É verdade que os fenômenos designados sob a denominação de fracasso escolar são mesmo reais. Mas não existe um objeto "fracasso escolar", analisável como tal. Para estudar o que se chama de fracasso escolar, deve-se, portanto, definir um objeto que possa ser analisado (CHARLOT, 2000, p. 16).

Outra ideia que permeia o âmbito educacional, e que o autor desconstrói, é sobre a origem social do fracasso escolar. Nas escolas, é muito comum os educadores atribuírem à posição social das famílias e ao contexto sociocultural o fracasso escolar das crianças. Os estudos de Charlot demonstram que essas ideias surgiram a partir da interpretação equivocada das teorias da sociologia, reproduzidas nos anos 1960 e 1970, tendo como principais autores Pierre Bourdieu e Jean Claude Passeron. A difusão de tais teorias apresenta muitas possibilidades, mas, também, limites, perspectivas restritas, e incontáveis erros de entendimento por parte dos educadores. De acordo com Charlot, os resultados propagados por essas deturpações das teorias "[...] têm sido amplamente utilizados para afirmar que a origem social é a causa do fracasso escolar e que os alunos em situação de fracasso padecem de deficiências socioculturais [...]" (CHARLOT, 2000, p. 17). Nesse contexto, a culpa do fracasso escolar é totalmente vinculada ao aluno e definida por suas condições sociais e carência cultural, uma perspectiva determinista e tendenciosa que atribui à realidade um caráter imutável e desconsidera a possibilidade pragmática de encontrar soluções para os problemas, predestinando o aluno ao insucesso, conforme opina o estudioso francês:

A sociologia dos anos 60 e 70 analisou o fracasso escolar em termos de diferenças entre posições sociais. [...]. Além disso, foi interpretada pelos docentes e pela opinião geral em termos de origem social, de deficiências e de causalidade, o que é totalmente abusivo. Houve, assim, uma imposição progressiva da "leitura negativa" do fracasso escolar e, mais geralmente, da escolaridade das crianças das famílias de categorias sociais populares (CHARLOT, 2000, p. 19).

A reprodução da teoria sociológica fundamentada no conceito de habitus que é definido pelo sociólogo Pierre Bourdieu como sendo

Um sistema de disposições duráveis e transponíveis que, integrando todas as experiências passadas, funciona em cada momento como uma matriz de percepções, apreciações e ações - e torna possível a realização de tarefas infinitamente diferenciadas, graças às transferências analógicas de esquemas, que permitem resolver os problemas da mesma forma, e às correções incessantes dos resultados obtidos, dialeticamente produzidas por esses resultados (BOURDIEU; ORTIZ, 1983, p. 65).

Que explica o fracasso escolar por meio da diferença da posição que o aluno ocupa no espaço social e escolar. Essa posição é determinada pela posição social dos pais, conforme explica Charlot: “As sociologias da reprodução têm estabelecido a existência de uma correlação 
estatística entre as posições sociais dos pais e as posições escolares dos filhos" (CHARLOT, 2000, p. 23). Assim, as crianças oriundas de famílias desfavorecidas então sujeitas ao fracasso escolar devido à sua origem de classe. Outra interpretação realizada sob a ótica da teoria das sociologias da reprodução para denunciar o fracasso escolar é pensar a diferença como deficiência sociocultural. Segundo Charlot: "A teoria da deficiência sociocultural pratica uma leitura 'negativa' da realidade social, que ela interpreta em termos de falta" (CHARLOT, 2000, p. 29). Ainda de acordo com esse autor, a partir desta perspectiva, o aluno passa a ser pensado como um objeto, assim como o que lhe falta, suas lacunas e carências o que, na opinião do estudioso, seria equivocado:

\begin{abstract}
Afirmar que a origem social é a causa do fracasso escolar é cometer dois erros. Por um lado, significa passar de variáveis construídas pelo pesquisador [...] para realidades empíricas [...]. Por outro, é interpretar um vínculo, também construído em termos de causa efetiva, de ação empírica. É verdade que o fracasso escolar "tem alguma coisa a ver" com a origem social [...] mas a origem social não produz o fracasso escolar (CHARLOT, 2000, p. 25).
\end{abstract}

Ou seja, ao considerar a origem social como único fator responsável pelo fracasso escolar, os professores, além de adotar uma postura de percepção da realidade, concebida e restrita a partir de suas ideias e julgamentos, considera essa realidade como algo dado, imutável, o que desmotiva a sua participação em um processo intervenções para melhoria da situação de aprendizagem dos alunos.

Charlot (2000) acredita que há uma correlação entre o fracasso escolar e as desigualdades sociais, mas não admite que esta explicação seja suficiente para justificar o fracasso de muitos alunos, fenômeno que envolve uma complexidade de situações. O autor também não atribui exclusivamente à família a responsabilidade pelo fracasso escolar dos alunos.

Com o objetivo de provar que as explicações que atribuem à origem social e ao contexto familiar as causas do fracasso escolar são incompletas o autor faz questionamentos sobre o sucesso que alguns alunos das classes menos favorecidas têm na escola. Como explicar esse fato a partir da teoria da reprodução? Para justificar esse questionamento, segundo Charlot (2000), os docentes utilizam a noção de dom. Para eles, enquanto alguns alunos pertencentes a famílias populares acabariam por fracassar na escola devido às deficiências socioculturais advindas da origem familiar, outras crianças conseguiriam esquivar-se por serem "bem dotadas".

$\mathrm{O}$ autor defende a proposição de que a teoria de origem familiar e da deficiência 
sociocultural trata-se de uma constatação, de uma construção teórica advinda da experiência dos docentes e de uma interpretação subjetiva realizada de acordo com interesses ideológicos que proporcionam benefícios aos próprios professores, uma vez que: “[...] preserva-os de qualquer crítica direta: o fracasso escolar não é imputável às práticas docentes, mas, sim, aos alunos e às suas famílias" (CHARLOT, 2000, p. 29). Os adeptos de tal ponto de vista estão convencidos de que o fracasso escolar incide sobre o aluno desprovido de competências necessárias ao ambiente escolar, e que a causa para tal teria origem no âmbito familiar, responsável pela produção das deficiências e, consequentemente, pelo fracasso escolar.

Esta postura de culpabilizar alunos ou seu contexto social contribui para que as deficiências do processo de ensino sejam cristalizadas, eximindo a escola de se comprometer com a busca de soluções para os problemas de aprendizagem que surgem no cotidiano escolar.

Para que haja uma mudança nessa situação, Charlot (2000) propõe a prática epistemológica e metodológica de uma leitura "positiva" dos alunos, segundo a qual o educador deve ater-se ao que os alunos conseguem realizar, deixando de ressaltar somente suas falhas e carências. Para tanto, é preciso compreender como se construiu o aprendizado de um aluno que fracassa e entender qual o sentido que ele atribui à situação, reforçando aquilo que é produtivo. Nas palavras de Charlot: "A leitura positiva busca compreender como se constrói a situação de um aluno que fracassa em um aprendizado e, não, 'o que falta' para essa situação ser uma situação de aluno bem-sucedido" (2000, p. 30). A prática da leitura positiva concebe o indivíduo enquanto sujeito que, mesmo reconhecendo a sua posição de subjugação, o instiga a raciocinar, interpretar o mundo e a transformá-lo em seu proveito. A prática da leitura positiva pode ser desenvolvida pelos educadores em consonância com o desenvolvimento da consciência crítica.

A escola tem um compromisso social com os seus alunos: precisa entender e compreender a história que constitui cada um desses indivíduos, inseridos dentro desse universo escolar, para que seja possível o enfrentamento dos desafios impostos pela diversidade presente nesse espaço e o atendimento das novas demandas educacionais exigidas pela sociedade atual.

\section{A importância da escola e do professor na gestão do processo de aprendizagem}

Ao problematizar o fracasso escolar e a democratização do ensino, pretende-se provocar a reflexão sobre os elementos que constituem e impactam na qualidade do ensino e as concepções 
que se revezam nas discussões sobre educação pública. Paro (2012) identifica como estreita a concepção de educação que se destina à mera transmissão de conhecimento e informações às novas gerações. Para o autor, uma concepção radicalmente democrática volta-se para o preparo dos sujeitos ao exercício da cidadania, e, necessariamente, envolve todos os conhecimentos que compõem a cultura historicamente construída. Além disto, o que o autor identifica como baixo desempenho dos alunos egressos do ensino fundamental, que retêm uma parcela mínima dos conhecimentos desenvolvidos nos currículos escolares ao longo dos anos, é explicado pela inadequação do objetivo de "transmissão de conhecimento":

Isso acontece porque a pequenez desse objetivo não tem implicações apenas políticas subestimação do que é necessário em termos educativos para o exercício da cidadania mas também técnicas, sendo que estas guardam uma estreita dependência das implicações políticas (PARO, 2012, p. 32).

O espaço escolar e o professor podem contribuir enormemente para uma formação cidadã fundamentada em direitos tanto quanto em valores humanos, tais como amor, solidariedade, honestidade, justiça, gratidão, humildade, respeito, tolerância e responsabilidade, na medida em que a instituição possibilita a reflexão crítica sobre os princípios, as normas e a ética que se pretende construir na sociedade, a partir de uma postura de autoconsciência do papel de cada um no mundo. A escola pode, portanto, interferir na realidade de seus educandos, incentivando, por meio da educação, uma atitude responsável, tornando-os agentes transformadores do meio em que vivem e garantindo, assim, a melhoria da qualidade de vida em comunidade.

Paro (2012) esclarece que o componente técnico do processo educativo se refere ao modo como o aluno se apropria da cultura historicamente produzida. Educar envolve uma dimensão política, e, como processo de trabalho, envolve o produtor (professor) e o objeto de trabalho (aluno). Porém, o "objeto" é também sujeito, e não é possível pensar a ação do professor de maneira unilateral, mas em interação constante com o aluno, em relação dialógica. Por isto o sistema escolar produz fracasso, pois ainda prevalece o modelo do professor como agência de comunicação de conhecimentos, sem considerar a relação dialógica que torna tão específico o trabalho educativo. A ideia de mediação no processo educativo sinaliza para a importância de que o professor saiba intervir "no sentido de prover condições e modos de assegurar a relação cognitiva e interativa dos alunos com os objetos de conhecimento" (LIBÂNEO, 2013, p. 33). As especificidades do processo educativo incluem pensar o papel que o professor exerce perante seus alunos, o que pode facilitar ou inibir a produção do conhecimento. 
Complementando esta análise, Charlot (1996) elabora uma argumentação sobre a relação que o aluno estabelece com o saber. O termo relação com o saber é definido como o estabelecimento de sentido e valor entre o sujeito e o que este sujeito aprende. Desta forma, o que está em jogo no processo educativo é a relação epistêmica com o saber: "Aprender é se apropriar do saber, construir um sentido, saber como se conduzir em qualquer circunstância, cumprir suas obrigações profissionais de escolar" (CHARLOT, 1996, p. 49). E a reflexão que precisa ser feita é se a escola pública tem desempenhado este papel na vida dos educandos, se os objetivos definidos nos currículos contemplam esta dimensão do conhecimento. Paro (2000) afirma que “trata-se de, na busca de objetivos, não perder de vista as mediações necessárias para concretizálos" (p. 32), pois, segundo o autor, qualquer projeto de escola pública de qualidade passa pela ação e relação dos sujeitos envolvidos no processo educativo.

Charlot (2005) enfatiza a importância das práticas das escolas e dos professores e salienta a relevância desses no processo de ensino-aprendizagem. De acordo com o autor, no momento em que o professor ensina e o aluno não aprende, o professor que continua ensinando - e não considera o processo de aprendizagem do aluno - acaba por contribuir para a construção do fracasso escolar no cotidiano da sala de aula. Para evitar que isso ocorra, os professores precisam conhecer as demandas específicas dos seus alunos e utilizar métodos que tenham por finalidade a mobilização do sujeito no seu processo de aprendizagem.

Convém ressaltar que o professor, como mediador do processo de aprendizagem de seus alunos, adquire um papel de extrema importância, tanto por se constituir em uma figura de referência do conhecimento formal como por se configurar como um agente imbuído da autoridade acadêmica e social, potencialmente capaz de contribuir para a articulação dos saberes e, assim, para o enfrentamento dos problemas locais da comunidade.

Por exemplo, ao estudar um conteúdo de Ciências, o professor pode desenvolver projetos com seus alunos, que identifiquem em que aquele conteúdo se relaciona com a comunidade dos alunos, com suas próprias histórias, resgatando a cultura local e identificando elementos que se articulam com o conteúdo, tornando-o significativo. Da mesma forma, os demais conteúdos podem - e devem - se articular com a realidade local, tornando os alunos, de fato, sujeitos construtores de seu conhecimento, e não meros repetidores de teorias, conceitos e fórmulas. Ao resgatar e valorizar a realidade local, o professor aproxima a educação formal da própria experiência de seus alunos, tornando o conhecimento um processo significativo e estimulante. 
Neste sentido, os aportes sobre desenvolvimento local contribuem para se pensar em alternativas pedagógicas que estimulem a relação dos alunos com o saber. O conceito de desenvolvimento local é, complexo e envolve uma série de variáveis e agentes, devendo ser trabalhado sobre diferentes perspectivas. Fragoso (2005, p. 64) define o desenvolvimento local como: “[...] possibilidade das populações poderem expressar uma ideia de futuro num território visto de forma aberta e flexível, onde esteja ausente a noção do espaço como fronteira, concretizando ações que possam ajudar à (re)construção desse futuro".

Para o autor, o maior objetivo da educação é promover a qualidade de vida das pessoas, favorecendo o aumento do nível de autoconfiança e a organização social, de forma a empoderar ${ }^{1}$ os sujeitos, para que sejam capazes de provocar as mudanças que precisam ser promovidas.

Considerando esses fatores, a educação para o desenvolvimento local promove as mudanças a partir da atuação dos sujeitos em suas próprias realidades. Vislumbrando um futuro melhor, desde uma perspectiva aberta, permeável e flexível, estes propõem ações concretas a partir de um processo pedagógico coletivo, que amplia as noções de território e desenvolve um empreendimento comunitário e partilhado. Nas palavras de Fragoso: "A mudança seria uma característica central sem a qual não poderíamos dizer que ocorreu desenvolvimento e seria fundamental a articulação com agentes, processos e entidades externas ao local” (FRAGOSO, 2005, p. 64). A participação dos sujeitos no processo de mudança é a essência da educação para o desenvolvimento local, e as mudanças dão sentido à ação dos sujeitos [...], "sem as quais não tem sentido o movimento de análise da própria situação contextual das populações” (FRAGOSO, 2005, p. 68).

Assim, a escola também se apropria da realidade local, contribuindo para a construção de uma identidade coletiva, na medida em que valoriza e considera as diferentes dimensões da coletividade. Esta perspectiva está diretamente comprometida com a formação das gerações futuras, conforme enfatiza Dowbor, pois há "necessidade de se formar pessoas que amanhã possam participar de forma ativa das iniciativas capazes de transformar o seu entorno, de gerar dinâmicas construtivas" (DOWBOR, 2009, p. 22).

Se a escola consegue tornar o aprendizado uma experiência rica de sentidos, estará contribuindo para um aumento na qualidade de vida e no bem estar tanto de seus alunos, como da

\footnotetext{
$1 \mathrm{O}$ conceito de empoderamento está relacionado à autonomia dos indivíduos ou grupos tomarem decisões e realizarem ações sobre questões que lhes dizem respeito.
} 
comunidade local, uma vez que a participação na vida em coletividade é uma das necessidades primordiais do ser humano.

Por isso, é interessante que o planejamento do trabalho educativo contemple a participação do aluno e da comunidade, tanto na escolha da metodologia, dos conteúdos, do tipo de avaliação, como no acompanhamento participativo de todo o processo de ensino e aprendizagem, o que exercita enormemente a democracia. Conforme Fragoso, "isto implica, por exemplo, que as pessoas tenham uma palavra a dizer sobre as suas próprias formações, que possam pronunciar-se sobre o desenho, os conteúdos, as metodologias usadas e a própria avaliação" (FRAGOSO, 2005, p. 68). Daí a importância de a equipe pedagógica estar suficientemente entrosada e disposta a colaborar com cada membro, para que o trabalho surta o resultado esperado.

Uma vez que o trabalho pedagógico direciona-se à formação dos alunos para a participação cidadã, espera-se que esses sejam capazes, tanto de adquirem os conhecimentos científicos necessários, como de atuarem em suas comunidades, de forma a produzirem mudanças nos aspectos negativos, intervindo consciente e criticamente e promovendo a melhoria da qualidade de vida, tanto no nível pessoal, como no nível comunitário.

A integração do currículo escolar às demandas da comunidade, ampliando os horizontes no conhecimento da realidade local, pode contribuir para alteração dos aspectos que precisam ser modificados e potencializar as oportunidades de aprendizagem aos alunos, o que está estreitamente relacionado com a educação para o desenvolvimento local. Isto é referenciado por Góes e Machado (2013, p. 632):

\footnotetext{
Ademais é esperado que a escola propicie o ambiente e o espaço favoráveis a isto, que haja o envolvimento e interesse dos professores em desenvolver projetos que vislumbrem uma prática educativa inovadora e que o processo pedagógico esteja centrado na aprendizagem do aluno.
}

Neste contexto em que a escola vem redimensionando o seu papel e sua função social, torna-se fundamental o reconhecimento de sua importância na inovação e construção das interações sociais que perpassam os seus muros para que suas ações sejam capazes de contemplar o desenvolvimento local.

As práticas pedagógicas são imbuídas de intencionalidades, que abarcam as esferas éticas, didáticas, sociais e políticas. Assim, a transmissão de "saberes públicos a todos, que apresentam 
SILVA, Karina Barreto; AFONSO, Maria Lúcia Miranda. Democratização do ensino e o fracasso escolar.

um valor, independentemente de circunstâncias e interesses particulares, em função da formação geral” (LIBÂNEO, 2005, p. 53), pode coexistir com uma postura crítica, investigativa, transformadora, que reconhece as diferenças, valorizando-as e articulando a formação geral à cultura local.

Assim, o autor enumera quatro desafios que as escolas precisam enfrentar, iniciando com o debate a respeito da ideia de universalidade em contraponto com a relatividade. Para Libâneo, “os valores e práticas são produtos socioculturais, portanto decorrentes do modo de pensar e agir de grupos sociais particulares" (2005, p. 24). Isto leva ao questionamento quanto à possibilidade de se adotar uma posição relativista em relação à cultura e valores que devem ser ensinados pelas escolas, sem que se desconsidere as culturas particulares. O desafio é exatamente prover a cultura geral, independentemente de contextos particulares, mas conciliando-a com as exigências sociais das diferentes comunidades.

Outro dilema colocado pelo autor refere-se ao currículo e às práticas escolares, que podem priorizar o aspecto cognitivo ou experiencial, a partir do que a escola valoriza como aprendizagens significativas:

Para quem põe o foco nas mediações cognitivas como instrumento para desenvolvimento do pensamento, o currículo e as práticas escolares estariam voltados para a internalização de elementos cognitivos, de bases conceituais, para lidar com a realidade, sem descartar a motivação do aluno, sua subjetividade e contextos de vida. Para quem defende um currículo experiencial, o conhecimento escolar estaria na experiência sociocultural, na convivência e nas práticas de socialização, isto é, a cultura "escolar" estaria subordinada aos saberes de experiência de que são portadores os alunos, dissolvendo-se a disciplinaridade em favor de um conteúdo mais próximo às manifestações culturais (LIBÂNEO, 2005, p. 52).

Libâneo indaga se a aprendizagem de conteúdos científicos é incompatível com os processos de pensamento, sugerindo a possibilidade de se incorporar no currículo escolar tanto os conteúdos científicos como a experiência sociocultural, o contexto social e as características psicológicas dos alunos (2005, p. 51). Isto sugere que as escolas precisam repensar suas práticas, rompendo com a perspectiva hegemônica de priorizar os conteúdos científicos, mas descolandoos da realidade sociocultural dos alunos. Naturalmente, isto irá impactar na forma como o aluno se relacionará com o conhecimento, conforme apontado anteriormente por Charlot (2005), quando se refere ao saber imaginário, mágico ou realista, uma vez que a atividade intelectual não faz nenhum sentido, já que "o que se faz não tem sentido como atividade, mas é absolutamente essencial para se ter uma vida normal no futuro" (CHARLOT, 2005, p. 118). O conhecimento 
desvinculado da experiência real do aluno só se justifica por um vir-a-ser, o que torna a relação que o aluno estabelece com o saber uma relação desconectada de suas necessidades como sujeitos históricos e sociais.

Um terceiro dilema identificado por Libâneo (2005) diz respeito às formas de organização institucional da escola, que são realizadas conforme as opções relacionadas às questões anteriores. Isto é, a partir das escolhas que a escola fizer em relação ao currículo e à ideia de relatividade e universalidade, serão adotadas regras de funcionamento que possibilitem o alcance dos objetivos pedagógicos a que se destina:

De um lado, se porá a necessidade de as escolas terem seu funcionamento submetido a regras mínimas racionalmente justificadas em função de se estabelecer um clima adequado ao trabalho intelectual, acompanhando a postulação universalista da formação científica e cultural para todos. De outro, se argumentará que essa moral universal válida "per se" não pode existir, precisamente porque ela depende de contextos particulares da vida dos alunos e da comunidade (LIBÂNEO, 2005, p. 52).

Os processos e procedimentos de regulação da vida escolar podem servir tanto para construir uma consciência crítica em relação ao papel social da escola, como para legitimar a desigualdade e a discriminação. Por isto, o desafio se constitui em criar as condições necessárias para o trabalho intelectual, a partir das escolhas metodológicas e curriculares que a escola faz.

Por fim, o quarto dilema se refere à escolha entre dois significados da educação inclusiva. O primeiro deles considera a educação inclusiva na perspectiva da socialização, do reconhecimento das diferenças, do respeito aos diferentes ritmos de aprendizagem e condições mentais, físicas e psicomotoras. Nesta concepção, o conhecimento dito científico estaria subordinado às experiências de socialização dos alunos. O segundo significado considera a educação inclusiva como aquela capaz de "prover as condições intelectuais e organizacionais para se garantir a qualidade cognitiva das aprendizagens" (LIBÂNEO, 2005, p. 53), priorizando a aprendizagem do pensamento teórico, o domínio das ações mentais superiores e a aquisição dos "instrumentos e procedimentos lógicos pelos quais se chega aos conceitos e ao desenvolvimento cognitivo" (LIBÂNEO, 2005, p. 53). Libâneo concebe a educação inclusiva como aquela que preocupa-se em oferecer as condições necessárias em suas práticas e escolhas curriculares para garantia da centralidade do conhecimento e da aprendizagem nas escolas. Isto não significa desconsiderar as experiências pessoais, culturais e sociais de seus alunos, mas promover, de fato, uma inclusão social, reconhecendo tanto a diversidade como a universalidade da cultura escolar. 
É nesta direção que entende-se o desenvolvimento local, como fator propulsor de mudanças necessárias. É aconselhável desmistificar as causas do fracasso escolar que até hoje vem sendo traduzidas pelos profissionais da educação como efeito da teoria do dom, pelo discurso das "deficiências sócio-culturais", respaldados pela teoria da reprodução social. O trabalho pedagógico pode ser direcionado para o reconhecimento das lutas de classes e pela opção pelas classes subalternas, no sentido de legitimar suas lutas. Por mais utópico que esse pensamento pareça ser na atualidade, é interessante perceber que a escola, hoje, continua legitimando um sistema opressivo e desqualificando os saberes populares, ao mesmo tempo em que envereda na armadilha da baixa qualidade do ensino como se este fosse o determinismo dos quais os pobres não podem se desvencilhar. Se a escola, compreendida no conjunto de trabalhadores que atuam em seu interior, apropriar-se das demandas locais e buscar contribuir para a solução dos problemas da comunidade, articulando-se com outros atores sociais, no nível local, poderá contribuir para a construção da consciência cidadã de seus alunos, ao mesmo tempo em que reconstrói sua identidade e seu papel na comunidade.

A escola passa a ser (co)responsável não só pela formação do indivíduo que ela educa, como também passa a ter maior compromisso social, configurando-se como um importante ator social e agente das mudanças necessárias, pois é no ambiente escolar que serão fomentadas as condições para o exercício da autonomia e do protagonismo social.

Assim, a inovação educacional torna-se estratégica, pois pode contribuir para alcançar objetivos definidos a partir de uma realidade local.

\section{Movimentos para a inovação educacional}

Na perspectiva da educação para o desenvolvimento local, compreende-se que a escola pode contribuir para a transformação das sociedades, e as inovações se constituem instrumentos que irão favorecer o processo educativo, tornando-o interativo e comprometido com a atividade intelectual. A capacidade de inovar é decisiva para alterar relações estagnadas com o saber e a implicação crítica dos professores, envolvendo-se no debate político sobre a educação e refletindo sobre as necessidades de seus alunos, poderá propiciar uma aprendizagem mais significativa.

$\mathrm{Na}$ atualidade, muitas são as propostas implementadas na rede de educação com o 
objetivo de melhorar a qualidade de ensino e de promover mudanças na educação, que podem estar de acordo com o conceito que Carbonell (2002) utiliza para definir inovação, "como um conjunto de intervenções, decisões e processos, com certo grau de intencionalidade e sistematização, que tratam de modificar atitudes, ideias, culturas, conteúdos, modelos e práticas pedagógicas" (p. 19). Percebe-se, na elaboração do conceito, a preocupação do autor com a intencionalidade e a sistematização, o que demonstra que a educação para o desenvolvimento local não difere do rigor metodológico da educação tradicional.

Porém, para o autor, essa definição é multidimensional e aberta a inúmeras interpretações, uma vez que, não se pode negar que as ações educativas são imbuídas de ideologias, influenciadas pelos contextos socioculturais e pelas políticas econômicas e educativas (CARBONELL, 2002). Mais que inovar o discurso nas escolas, o desafio que se coloca é o de modificar as práticas pedagógicas que acontecem dentro das instituições e (re) adequá-las aos educandos e à realidade local, vislumbrando a autonomia dos alunos e sua formação participativa na comunidade.

Para Charlot (2005), a inovação é a capacidade de resolução dos problemas, mobilizando os recursos necessários para isto. O autor afirma que ser professor, portanto, deixa de ser missão ou função, e passa a ser profissão, pois os professores são profissionais capazes de resolver problemas, de maneira especializada.

Na esteira das discussões sobre inovação educativa, Miguel Arroyo (1999) alerta para as reformas educacionais, pretensamente inovadoras, comumente adotadas na cultura política brasileira, que não percebem o sistema educativo como um todo e centram as ações nos projetos de capacitação de professores e na revisão dos currículos, destacando o estilo de diagnosticar a sociedade, as instituições, as escolas, os currículos, os professores e os alunos sob uma ótica negativa:

\begin{abstract}
Quando se proclama que a escola está em crise ou tem baixa qualidade, não se demonstra, como prova, que a repetência e a evasão continuam altas, que a escola não é capaz de fazer com que nossa infância e nossa adolescência aprendam os conteúdos do programa? Consequentemente, a inovação escolar visará basicamente aumentar o êxito ou diminui o índice de fracasso na aprendizagem dos conteúdos predeterminados e programados (ARROYO, 2000, p. 137).
\end{abstract}

A inovação educacional, portanto, deve evitar o reducionismo comum nas inovações apresentadas de cima para baixo, sem a participação dos principais interessados na melhoria da 
qualidade do ensino: professores, famílias, alunos, sociedade. Esta análise corrobora a proposição de que a qualidade da educação pública passa, necessariamente, pela sua capacidade de educar para a democracia (PARO, 2000).

Para Carbonell (2002) a inovação educacional pode estar aliada à renovação pedagógica, como também pode se relacionar à mudança e melhoria. Nessa perspectiva, a mudança, nem sempre, pode acarretar a melhoria, mas segundo o autor, toda melhoria implica mudança.

É preciso entender a diferença existente entre inovação e reforma, uma vez que, essas palavras são determinantes no que tange as mudanças educacionais a serem implementadas. A palavra reforma está vinculada ao sistema educativo e movida por imperativos econômicos e sociais, por vezes apresentam-se de maneira isoladas com o objetivo de resolver todas as demandas existentes, um dos principais motivos do seu insucesso. Já a inovação, não pode ser vista, apenas, como a modernização da escola, a utilização da tecnologia (como o uso dos computadores) e a realização de excursões. Isto é, não pode se voltar para acessórios ou aparências, mas considerar e refletir sobre ações que facilitem o processo de aquisição do conhecimento e que apontem para a formação integral do aluno (CARBONELL, 2002).

A inovação busca melhorar o processo de ensino-aprendizagem, e não se resume a atender ao modernismo educacional, como se observa nos dias atuais, em que há um aparecimento rápido de ideias e, simultaneamente, o seu declínio, com ideias e ações descontinuadas e desconectadas. As propostas de inovação, buscando solucionar problemas da educação, contemplam o desenvolvimento de ações que permitirão o alcance e abrangência dos resultados esperados. A complexidade acerca do processo de inovação dos processos educacionais é discutida por Carbonell (2002, p. 81):

Um projeto educativo inovador expressa finalidades e esperanças no futuro; histórias e narrações compartilhadas; objetivos globais relativos à personalidade dos alunos, seu desenvolvimento social e suas aprendizagens; concepção sobre a vivência e a maneira de enfrentar os conflitos; mecanismos para a participação democrática dos diversos estamentos e tomada de decisões; o modo como a escola se articula com o entorno; e fórmulas alternativas para mudar a destinação tradicional dos tempos e espaços.

A finalidade primordial da inovação é avançar na construção de ações que considerem a realidade dos educandos, considerados sujeitos histórico-culturais. A inovação educacional pretende o desenvolvimento do senso crítico e participativo do aluno, por meio de uma prática pedagógica consistente que leve à reflexão sobre a própria condição de cidadão, capaz de intervir 
na sociedade em que vive. Não se deve deixar de enfatizar a importância do envolvimento dos profissionais no desenvolvimento das ações do âmbito educacional.

A inovação das práticas e projetos educacionais ampliam a oportunidade de acesso ao ensino de qualidade para os educandos das camadas populares, uma vez que, a organização das ações praticadas nas escolas passam a ter como centro as demandas trazidas por esses alunos. "Um projeto inovador para a escola pública deve ser inclusivo e integrador de todo tipo de alunos, seja qual for a sua procedência social, seu "nível", necessidades e expectativas educativas" (CARBONELL, 2002, p. 81). A educação só conseguirá implementar ações inovadoras nas instituições se reconhecer as necessidades que apresentam os seus educandos e elaborar planejamentos que atendam a sua realidade, por meio de propostas que visem dialogar com as experiências trazidas por esses alunos para o âmbito educacional.

Sob esta ótica, Paro (2000) analisa que é possível discutir qualidade do ensino público a partir de suas contribuições para a prática social, o que contempla também a dimensão política e humana. Para o autor, o processo educativo também envolve uma prática social e a posse de saberes produzidos e apropriados historicamente:

Como tais saberes não envolvem apenas meras informações, mas o desenvolvimento livre de valores, crenças, posturas, comportamentos, hábitos, escolhas etc., faz-se necessário um processo educativo, que envolva a interação entre sujeitos livres, como o que pode (e deve) ser desenvolvido na escola (PARO, 2000, p. 29).

Assim, na análise de Paro (2000), a escola pode contribuir para a formação para a democracia, na medida em que conseguir desenvolver nos alunos as capacidades culturais para que possam participar ativamente da vida pública. A formação para a cidadania é, portanto, um dos papeis essenciais da escola, e a discussão sobre qualidade não pode prescindir deste aspecto.

Entende-se, portanto, que uma perspectiva democrática do ensino público perpassa pela reflexão crítica acerca dos objetivos que se pretende alcançar no processo educativo, pela construção do conceito de qualidade do ensino associado às necessidades da sociedade contemporânea, pela elaboração de estratégias de ensino vinculadas ao desenvolvimento local, pelo desenvolvimento de capacidades para a participação dos sujeitos na vida pública e pela adoção de práticas metodológicas inovadoras. 


\section{Considerações finais}

No presente trabalho, constatou-se que o processo de democratização do ensino representou avanços significativos na qualidade de vida da sociedade brasileira, mas trouxe também desafios importantes que o sistema educacional ainda precisa enfrentar de maneira mais eficiente.

A discussão sobre a qualidade do ensino é frequentemente reduzida à perspectiva neoliberal, sem que aspectos como valores e atitudes sejam considerados. Isto revela posicionamentos e escolhas que tornam a escola pública incapaz de cumprir a função de preparar para a cidadania, na medida em que as práticas escolares ainda priorizam a transmissão de conhecimentos. Avançar nesta construção representa problematizar o tipo de sociedade que vem sendo historicamente construída, os contextos sociais em que as mudanças acontecem e a necessidade de repensar criticamente a própria função da escola.

Neste sentido, percebe-se a importância de se desmistificar as questões sobre o fracasso escolar, que na percepção de muitos educadores, advém apenas do contexto sociocultural e familiar do aluno. Ou, conforme a percepção dos gestores, tem a ver com a má formação de professores, conteúdos inadequados ou sistemas avaliativos ultrapassados. Observa-se a necessidade de investigar as causas que promovem o fracasso escolar nas instituições e implementar ações que proporcionem a extinção desses fatores, não deixando, no entanto, de analisar criticamente o que está por trás dos discursos oficiais sobre fracasso ou sucesso escolar. Isto significa romper com um modelo educacional que priorizou as elites políticas e econômicas, e relegou às classes populares a educação tecnicista, voltada para a apreensão de habilidades meramente funcionais, sem vinculação com a vida dos sujeitos e com as aspirações das comunidades locais.

A partir dos estudos de Libâneo, percebe-se que os desafios impostos à educação na atualidade estão voltados principalmente para o currículo das escolas, que devem contemplar valores universais e valores particulares, bem como conteúdos científicos e experiência sociocultural. É preciso considerar os saberes populares e integrá-los aos saberes das instituições escolares de forma a promover uma aprendizagem significativa que supere a base de ensino conceituais e considere as experiências sociocultural dos alunos. Ao implementar ações que visem atender às especificidades dos educandos é preciso, também, considerar e conhecer os 
processos pelos quais os alunos constroem a relação com a aprendizagem.

Por outro lado, Arroyo (1999) chama a atenção para a visão reducionista das reformas educacionais, pretensamente inovadoras, mas que não consideram a participação dos principais atores do sistema educacional e os mais interessados em garantir uma educação de qualidade. Mais que discutir apenas currículos e programas, o autor alerta para a importância de se discutir os objetivos que se pretendem para a escola pública. O debate sobre a qualidade da educação é enriquecido pelas contribuições de Vítor Henrique Paro (2012), que defende que a educação pública de qualidade precisa se comprometer radicalmente com a formação de alunos capazes de intervir na vida pública, ou seja, é essencial que a educação pública seja uma educação para a democracia.

As principais contribuições de Charlot (1996) referem-se à problematização da relação que o aluno estabelece com o objeto de conhecimento. $\mathrm{O}$ autor mostra que o conhecimento desvinculado da experiência real e vivida pelos alunos não se configura como significativo e, portanto, produz o que é identificado como fracasso escolar.

Os estudos analisados demonstram como as realidades sociais dos estudantes interferem em seu desempenho escolar, desmistificando o senso comum de que as classes populares são "naturalmente" menos capazes de obterem sucesso escolar. A discussão revela que o currículo, as práticas e as metodologias utilizadas pelo sistema de ensino priorizam um tipo de clientela que, com a democratização do ensino, não é mais a única a ser atendida nas escolas.

A conquista da escolarização como direito universal revela a necessidade de democratização de práticas sociais e de construção de alternativas que tornem a sociedade mais capaz de exercer a cidadania e a democracia.

\section{Referências}

ARROYO, Miguel G. Fracasso/sucesso: um pesadelo que perturba nossos sonhos. Em Aberto, Brasília, v. 17, n. 71, p. 33-40, jan. 2000. Disponível em:

http://emaberto.inep.gov.br/index.php/emaberto/article/view/2100/2069. Acesso em: 12 mar. 2017.

ARROYO, Miguel G. Experiências de inovação educativa: o currículo na prática da escola. In:

MOREIRA, Antônio Flávio Barbosa (org.). Currículo: políticas e práticas. Campinas: Papirus, 1999. v. 3, p. 131-164.

BRASIL. Ministério de Educação e Cultura. LDB - Lei nº 9394/96, de 20 de dezembro de 1996. Estabelece as diretrizes e bases da Educação Nacional. Brasília: MEC, 1996.

BOURDIEU, Pierre; ORTIZ, Renato. Pierre Bourdieu. São Paulo: Ática, 1983. 
SILVA, Karina Barreto; AFONSO, Maria Lúcia Miranda. Democratização do ensino e o fracasso escolar.

CARBONELL, Jaume. A aventura de inovar: a mudança na escola. Porto Alegre: Artmed, 2002.

CHARLOT, Bernard. Relação com o saber e com a escola entre estudantes de periferia. Cadernos de Pesquisa, São Paulo, n. 97, p. 47-63, maio 1996. Disponível em:

http://publicacoes.fcc.org.br/ojs/index.php/cp/article/view/803/814. Acesso em: 21 jul. 2017.

CHARLOT, Bernard. Da relação com o saber: elementos para uma teoria. Porto Alegre: Artmed, 2000.

CHARLOT, Bernard. Relação com o saber, formação dos professores e globalização: questões para a educação hoje. Porto Alegre: Artmed, 2005.

DOWBOR, Ladislau. Educação e desenvolvimento local. In: MAFRA, Jason Ferreira et al. (Orgs.). Globalização, educação e movimentos sociais: 40 anos de pedagogia do oprimido. São Paulo: Instituto Paulo Freire, p. 22-36, 2009.

FRAGOSO, António. Contributos para o debate teórico sobre o desenvolvimento local: um ensaio baseado em experiências investigativas. Revista Lusófona de Educação, Lisboa, v. 5, n. 5, p. 63-83, 2005. Disponível em: http://revistas.ulusofona.pt/index.php/rleducacao/article/view/1008. Acesso em: 21 jul. 2017.

GÓES, Flávia Temponi; MACHADO, Lucília Regina de Souza. Políticas educativas, intersetorialidade e desenvolvimento local. Educação e Realidade, Porto Alegre, v. 38, n. 2, p. 627-648, abr.jun. 2013. Disponível em: http://www.scielo.br/pdf/edreal/v38n2/v38n2a16.pdf. Acesso em: 21 jul. 2017.

LIBÂNEO, José Carlos. Adeus professor, adeus professora? São Paulo: Cortez, 2013.

LIBÂNEO, José Carlos. As teorias pedagógicas modernas revisitadas pelo debate contemporâneo na Educação. In: LIBÂNEO, José Carlos; SANTOS, Akiko (Orgs.). Educação na era do conhecimento em rede e transdisciplinaridade. Campinas: Alínea, 2005. p. 19-62.

LIBÂNEO, José Carlos. Democratização da escola pública. São Paulo: Edições Loyola, 2002.

LIBÂNEO, José Carlos. Escola pública brasileira, um sonho frustrado: falharam as escolas ou as políticas educacionais. In: LIBÂNEO, José Carlos; SUANNO, Marilza Vanessa Rosa. Didática e escola em uma sociedade complexa. Goiânia: CEPED, 2011. p. 75-95.

PARO, Vitor Henrique. A didática e a estrutura da escola fundamental. In: FETZNER, Andréa Rosana (org.). Como romper com as maneiras tradicionais de ensinar? Reflexões didático-metodológicas. Rio de Janeiro: Wak, 2012. (Coleção Ciclos em Revista, v. 6, p. 15-47).

PARO, Vitor Henrique. Educação para a democracia: o elemento que falta na discussão da qualidade do ensino. Revista Portuguesa de Educação, Portugal, v. 13, n.1, p. 23-38, 2000.

PARO, Vitor Henrique. Gestão escolar, democracia e qualidade do ensino. São Paulo: Ática, 2007. 